\title{
Investigations on the synthesis and chemiluminescence of novel 2-coumaranones - II
}

\author{
Stefan Schramm, ${ }^{a}$ Luiz Francisco Monteiro Leite Ciscato, ${ }^{b}$ Pascal Oesau, ${ }^{a}$ Reimar Krieg, \\ Jan Frank Richter, ${ }^{\mathrm{c}}$ Isabelle Navizet, ${ }^{\mathrm{d}}$ Daniel Roca-Sanjuán, ${ }^{\mathrm{e}}$ \\ Dieter Weiss, ${ }^{\mathrm{a}, *}$ and Rainer Beckert ${ }^{\mathrm{a}}$
}

${ }^{a}$ Friedrich-Schiller-Universität, Institut für Organische Chemie und Makromolekulare Chemie, Humboldtstrasse 10, 07743 Jena, Germany

${ }^{b}$ Centro de Ciências Naturais e Humanas, Universidade Federal do ABC, Santo André, SP 09210-170, Brazil

${ }^{c}$ Universitätsklinikum Jena, Institut für Anatomie II, Teichgraben 7, 07743 Jena, Germany.

${ }^{d}$ Université Paris-Est, Laboratoire Modélisation et Simulation Multi Echelle, MSME UMR 8208 CNRS, 5 bd Descartes, 77454 Marne-la-Vallée, France

${ }^{e}$ Department of Chemistry - Ångström, Theoretical Chemistry Programme, Uppsala University, 75002 Uppsala, Sweden

E-mail: dieter.weiss@uni-jena.de

DOI: http://dx.doi.org/10.3998/ark.5550190.p009.044

\begin{abstract}
The optimized one-pot synthesis of 16 new 2-coumaranones containing a carbamate side-chain is described. Furthermore, the quantum yields for the base-activated chemiluminescence in the presence of oxygen was determined for all compounds, with a maximum of $5.9 \pm 0.1 \times 10^{-2} \mathrm{E}$ $\mathrm{mol}^{-1}$, and the application of these compounds as substitutes for usual bioluminescent and chemiluminescent reagents in bioassays is anticipated. A preliminary mechanistic pathway is also suggested, making use of recent developments regarding aspects of organic chemiluminescence, in agreement with both experimental and theoretical data available on the induced 1,2-dioxetanone decomposition as well as with the high efficiency of this reaction.
\end{abstract}

Keywords: 2-Coumaranone, chemiluminescence, chemiexcitation, 1,2-dioxetanones, $\alpha$ peroxylactones, CIEEL, firefly bioluminescence

\section{Introduction}

Firefly luciferine and coelenterazine are very important chemiluminescent compounds originally found in living organisms (respectively in Photinus pyralis and in several marine organisms across seven phyla); they are used extensively in several bioanalytical methods with as yet 
unmatched sensitivity. ${ }^{1}$ Despite the significance and large-scale utilization of those compounds, their synthesis is very laborious and expensive, resulting in limited availability of the compounds. We have suggested the substitution of luciferine and coelenterazine in bioanalytical methods by alkyl- and aryl-substituted 2-coumaranones (1), which are also very efficient chemiluminescent substrates, in recent publications. ${ }^{2,3,4,5}$ This substitution would be a solution to lower the costs of several efficient methods with no loss of sensitivity.

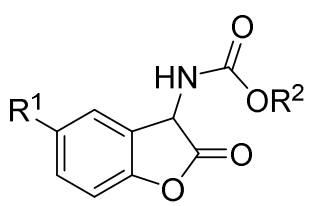

1

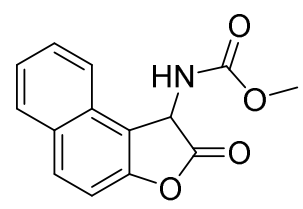

2

\begin{tabular}{cccccc}
\hline $\mathbf{1}$ & $\mathbf{R}^{\mathbf{1}}$ & $\mathbf{R}^{\mathbf{2}}$ & $\mathbf{1}$ & $\mathbf{R}^{\mathbf{1}}$ & $\mathbf{R}^{\mathbf{2}}$ \\
\hline $\mathrm{a}$ & $\mathrm{F}$ & $\mathrm{Me}$ & $\mathrm{i}$ & $\mathrm{F}$ & $\left(\mathrm{CH}_{2}\right)_{6} \mathrm{~N}_{3}$ \\
b & $\mathrm{Cl}$ & $\mathrm{Me}$ & $\mathrm{j}$ & $\mathrm{F}$ & $4-\mathrm{FC}_{6} \mathrm{H}_{4}$ \\
c & $\mathrm{Br}$ & $\mathrm{Me}$ & $\mathrm{k}$ & $\mathrm{F}$ & $2-\mathrm{BrC}_{6} \mathrm{H}_{4}$ \\
d & $\mathrm{F}$ & $\mathrm{Et}$ & 1 & $\mathrm{~F}$ & $2,4,6-\mathrm{Me}_{3} \mathrm{C}_{6} \mathrm{H}_{2}$ \\
e & $\mathrm{Cl}$ & $\mathrm{Et}$ & $\mathrm{m}$ & $\mathrm{F}$ & $4-\mathrm{MeOC}_{6} \mathrm{H}_{4}$ \\
f & $\mathrm{Br}$ & $\mathrm{Et}$ & $\mathrm{n}$ & $\mathrm{F}$ & $4-\mathrm{AcNHC}_{6} \mathrm{H}_{4}$ \\
g & $\mathrm{F}$ & $\mathrm{CH}_{2} \mathrm{C}\left(\mathrm{CH}_{3}\right)_{3}$ & o & $\mathrm{F}$ & $4-\mathrm{NO}_{2} \mathrm{C}_{6} \mathrm{H}_{4}$ \\
h & $\mathrm{F}$ & Propargyl & & & \\
\hline
\end{tabular}

Figure 1. Structure of chemiluminescent alkyl- (1a-i), aryl-substituted (1j-o) and naphthyl (2) 2-coumaranones synthesized in this work.

After the discovery of the chemiluminescence of 2-coumaranones by Lofthouse et al. ${ }^{6}$ in 1979, the reaction disappeared from scientific coverage for a long time, despite its simplicity and high chemiluminescence quantum yields. 2-Coumaranones display substantial chemiluminescent emission in polar aprotic solvents upon the addition of strong bases, such as DBU, $t$-BuOK and others. Current research is being carried out to optimize the emission in solvent/water mixture and in water triggered by enzymes, such as peroxidases (e.g. from horseradish, HRP) or ureases, or upon electrochemical reduction in a process known as electrochemiluminescence. 


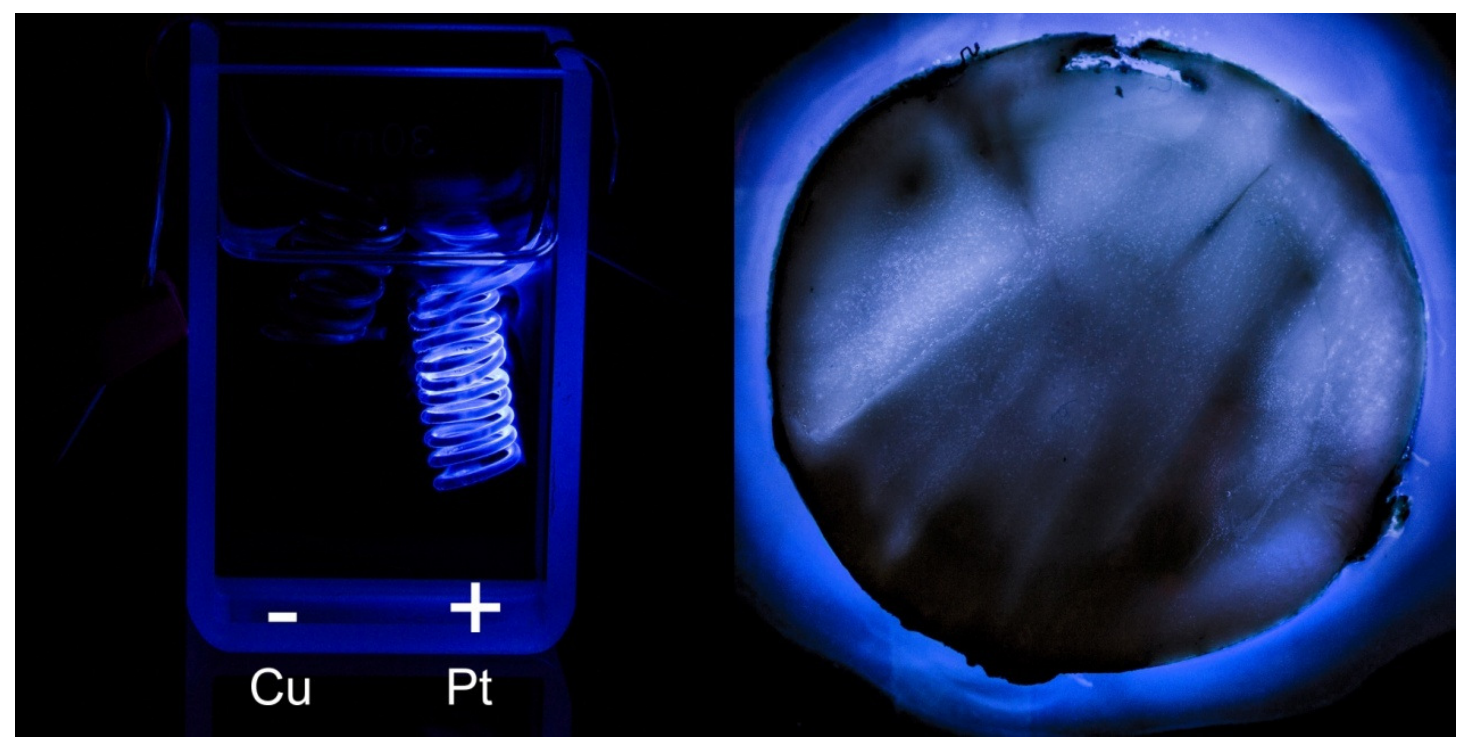

Picture 1. Left: electrochemiluminescence of 1d in DMF; right: acetonitrile solution of $\mathbf{1 d}$ on a freshly-cut slice of horseradish.

The proposed mechanism, able to explain the formation of excited states, is analogous to the one suggested for coelenterazine chemiluminescence, ${ }^{7,8}$ and involves several steps, as showed in Scheme 1. The sequential steps can be described as follows: $i$ ) deprotonation of the $\alpha$-carbon of the 2-coumaranone $(\mathbf{1}, \mathbf{2})$ by strong bases, forming a carbanion $(\mathbf{3})$ which is stabilized by the formation of a tautomer (4); $i$ ) the carbanion reacts with dissolved oxygen, supposedly via a single electron transfer (SET) step forming a pair of radical (5) and oxygen radical anion (superoxide); iii) a fast radical coupling step follows, generating the reactive deprotonated hydroperoxide $(\mathbf{6}) ; i v)$ this compound suffers a intramolecular nucleophilic addition followed by an elimination, forming the 1,2-dioxetanone (7). This is considered to be the essential highenergy intermediate (HEI) of the reaction that, by cleavage and extrusion of $\mathrm{CO}_{2}$ (step $v$ ), yields compound (8) at the singlet excited state; its decay to the ground state (step vi) emits light.

We confirmed in a previous article that the HEI for this reaction is indeed the 1,2dioxetanone $7^{5}$ this class of compounds are also proposed intermediates of firefly luciferine and coelenterazine luminescence; some of them have been prepared, isolated and used to produce chemiluminescent emission ${ }^{9}$, validating their ability to generate excited singlet states. For that reason, 2-coumaranones can be used as a reliable model system for generating very unstable 1,2dioxetanones in situ, without the need for difficult, laborious procedures. ${ }^{10}$

Ongoing with the previous work, we want to introduce new derivatives of 2-coumaranones, aiming towards the optimization of the synthesis. The newly established TsE-3CR (TscherniacEinhorn three-compound reaction) conditions are fundamental to this optimization, as we obtained better yields with less work and lower costs. Furthermore, the mechanism of the chemiluminescent reaction could be used to rationalize the dependence of the quantum yield 
with the new derivatives' chemical structure, for that, we will present the chemiluminescence absolute quantum yields of all new compounds in this article.

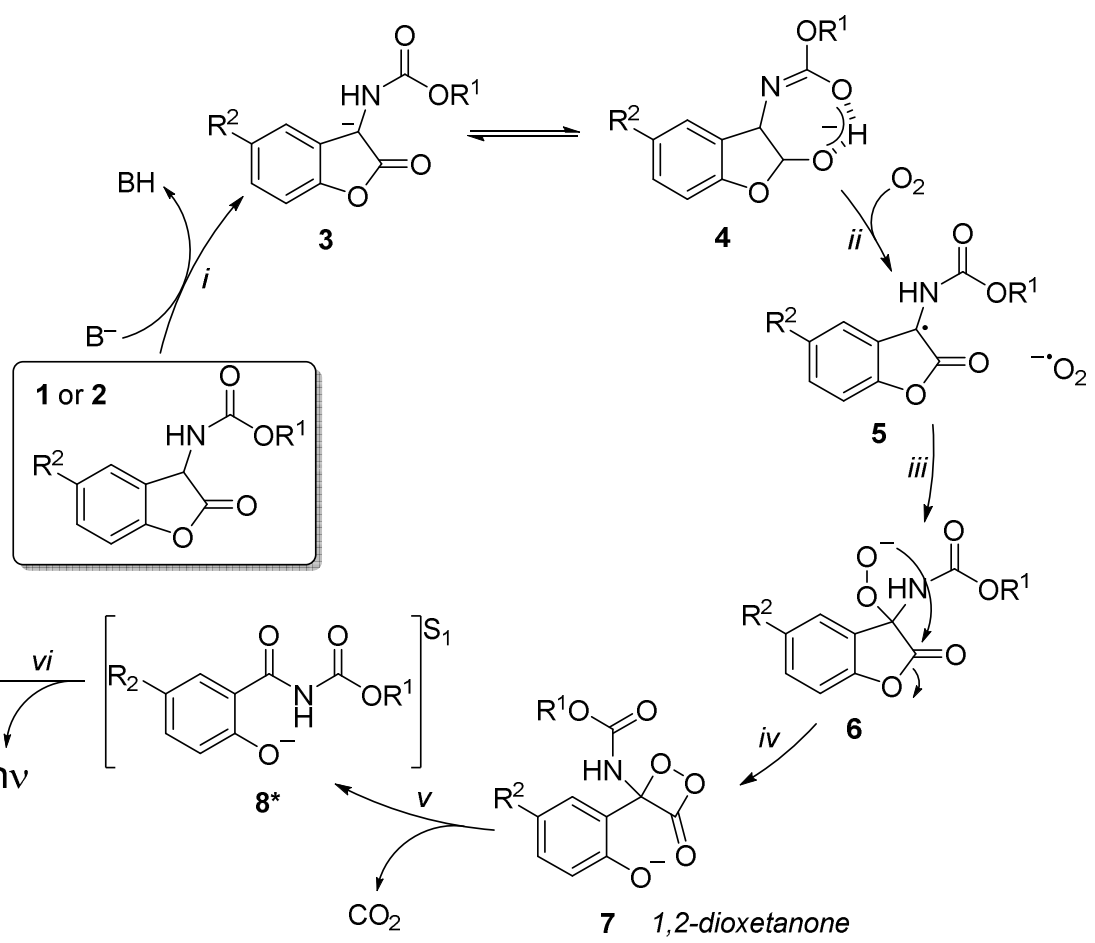

Scheme 1. Mechanism for the reaction of 2-coumaranones with a base in the presence of oxygen producing chemiluminescence.

\section{Results and Discussion}

\section{Synthesis}

All new compounds were synthesized via a "one-pot" Tscherniac-Einhorn reaction, ${ }^{11,12}$ in a considerably optimized way when compared to previous publications. ${ }^{2,3}$ Basically, it consists of a three-compound reaction, which is, therefore, referred to as TsE-3CR (Tscherniac-Einhorn three-compound reaction). The major difference to the reaction methodology developed by Matuszczak ${ }^{13,14,15,16}$ is that the final cyclization step forming a lactone can be omitted, resulting in a major yield improvement. 

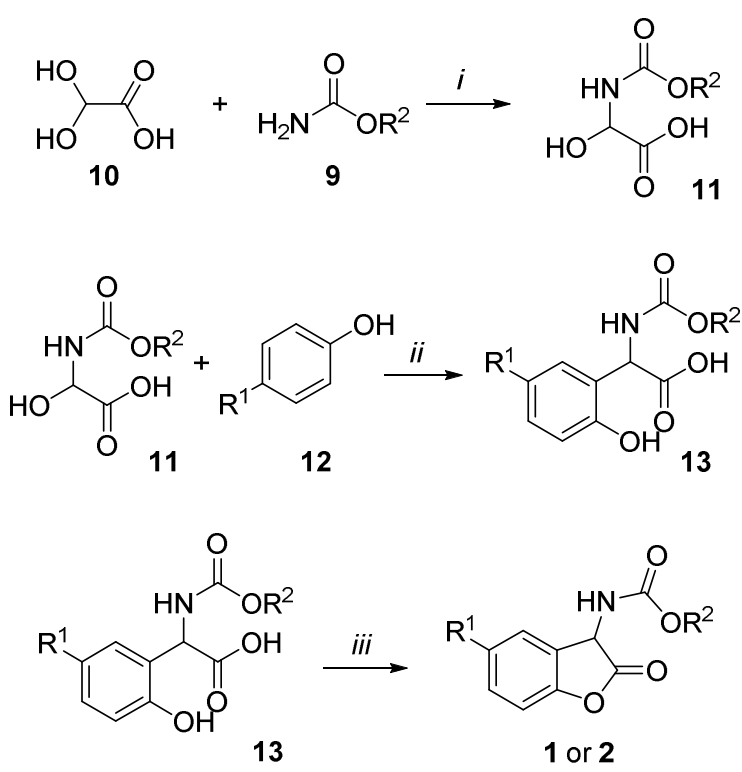

Scheme 2. The unoptimized synthesis of the 2-coumaronones 1 developed by Lofthouse. $i$ ) Acetone, reflux; ii) $\mathrm{AcOH} / \mathrm{H}_{2} \mathrm{SO}_{4}$ 9:1, r.t. (Tscherniac-Einhorn reaction); iii) $\mathrm{Ac}_{2} \mathrm{O}$, reflux.

The first step of the unoptimized synthetic route towards the target compounds ( $\mathbf{1}$ or $\mathbf{2})$ is the condensation of the carbamate (9) with glyoxylic acid monohydrate (10). The condensation product (11) is then used together with a para-substituted phenol derivative (12) as the starting material for the actual Tscherniac-Einhorn reaction. After the recrystallization of the solid product obtained (13), it has to be converted into the target compounds (1 or 2) by stirring it under reflux in acetic anhydride.

All three separately conducted reactions are condensations; therefore, it seemed to be worthwhile combining the three reactions into a single three-component reaction. In order to do this, all three starting materials $(\mathbf{9}, \mathbf{1 0}$ and 12) are used together in a Tscherniac-Einhorn reaction approach with slight modifications (Scheme 3). The reaction time seems to be the most crucial parameter in this reaction. With enough time (stretching from a few hours to a few days), the target compounds ( $\mathbf{1}$ or $\mathbf{2}$ ) can be produced directly with a considerable increase in the overall reaction yields.

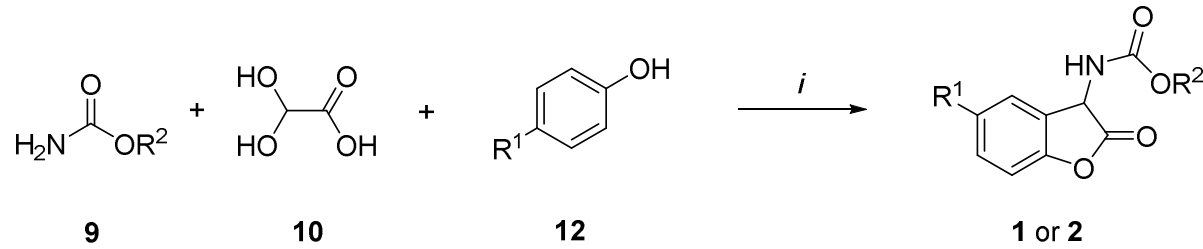

Scheme 3. Tscherniac-Einhorn three-compound reaction for the formation of 2-coumaranones 1 or 2. i) $\mathrm{AcOH} / \mathrm{H}_{2} \mathrm{SO}_{4}$ 9:1, r.t. 
A chemical equilibrium lies at the center of condensation reactions, and the shift of this equilibrium is determinant for an efficient synthesis. In this case, there is the formal production of three water molecules, whose removal, and therefore, equilibrium shift towards products, is made by the sulfuric acid present in the reaction mixture. Additionally, the products (1 or $\mathbf{2}$ ) are much less soluble in the mixture than the reactants, which is another factor that shifts the equilibrium favorably.

As a matter of fact, only one reaction mixture, one reaction vessel and one cleanup step are needed for this three-compound reaction synthesis. This means that the workload is reduced by a third compared to the synthesis in consecutive steps; a factor that enhances the productivity when applying this new TsE-3CR approach to prepare several new 2-coumaranones.

Table 1. Reaction time, melting point and isolated yield of the 2-coumaranones $\mathbf{1}$ and $\mathbf{2}$, synthesized by the TsE-3CR method

\begin{tabular}{|c|c|c|c|c|}
\hline Compound & & Reaction time & Melting point $\left({ }^{\circ} \mathrm{C}\right)$ & Isolated yield (\%) \\
\hline $1 \mathbf{a}$ & & 24 hours & 198 & 43 \\
\hline $1 b$ & & 6 days & 200 & 36 \\
\hline 1c & & 7 days & 208 & 27 \\
\hline $1 d$ & & 7 days & 156 & 24 \\
\hline 1e & & 5 days & 170 & 20 \\
\hline 1f & & 5 days & 182 & 20 \\
\hline $1 \mathrm{~g}$ & & 72 hours & 142 & 46 \\
\hline 1h & & 72 hours & 171 & 49 \\
\hline $\mathbf{1 i}$ & & 72 hours & 91 & 10 \\
\hline $\mathbf{1 j}$ & & 72 hours & 250 (dec.) & 51 \\
\hline $1 \mathbf{k}$ & & 48 hours & 220 & 68 \\
\hline 11 & & 72 hours & 245 & 87 \\
\hline \multirow[t]{4}{*}{$1 \mathrm{~m}$} & & 72 hours & 156 (dec.) & 31 \\
\hline & $1 n$ & & ours 208 & 36 \\
\hline & 10 & & 210 & 55 \\
\hline & 2 & & ours & 29 \\
\hline
\end{tabular}

\section{Chemiluminescence}

All new compounds carry a carbamate side chain as rest; both alkyl and aryl substituents on (1) were prepared. Preliminary experiments showed that 2-coumaranones with a carbamate side chain have a significantly stronger chemiluminescence than the 2-coumaranones with amide substructures described previously. ${ }^{2,3}$ Furthermore, the wavelength of the maximum emission intensity shifts hypsochromically compared to the compounds shown previously. ${ }^{2}$

The chemiluminescent emission of the compounds was triggered by the addition of a small quantity of DBU to an air-equilibrated solution of the 2-coumaranone in acetonitrile (MeCN). The intensity of light emission was followed in a spectrofluorimeter at chemiluminescence 
observation conditions, and instantly reaches its maximum, slowly decaying in few minutes in a first-order kinetic profile. The wavelength of the maximum chemiluminescent emission $\left(\lambda_{\mathrm{em}}\right)$ was determined for all compounds, and the wavelength of maximum fluorescence emission $\left(\lambda_{\mathrm{f}}\right)$ for the spent reaction mixtures. The absolute emission quantum yields were determined with luminol as a secondary standard. All these data are listed in Table $\mathbf{2}$.

Table 2. Maximum wavelength for the chemiluminescent emission $\left(\lambda_{\mathrm{em}}\right)$ of the compounds 1 and $\mathbf{2}$, maximum wavelength for the fluorescent emission $\left(\lambda_{\mathrm{fl}}\right)$ of the spent reaction mixture, observed rate constant for the decay of light emission $\left(k_{\mathrm{obs}}\right)$ and chemiluminescence quantum yield $\left(\Phi_{\mathrm{CL}}\right)$

\begin{tabular}{c|c|c|c|c}
\hline Compound & $\boldsymbol{\lambda}_{\text {em }}(\mathrm{nm})$ & $\boldsymbol{\lambda}_{\mathbf{f l}}(\mathrm{nm})^{\mathrm{a}}$ & $\boldsymbol{k}_{\mathbf{0 b s}}\left(\mathrm{s}^{-1}\right)$ & $\boldsymbol{\Phi}_{\mathbf{C L}}\left(\mathrm{E} \mathrm{mol}^{-1}\right) \times 10^{2}$ \\
\hline $\mathbf{1 a}$ & 436 & 437 & $0.013 \pm 0.005$ & $4.3 \pm 0.1$ \\
$\mathbf{1 b}$ & 427 & 428 & $0.0065 \pm 0.0001$ & $2.95 \pm 0.05$ \\
$\mathbf{1 c}$ & 427 & 428 & $0.0050 \pm 0.0002$ & $0.74 \pm 0.01$ \\
$\mathbf{1 d}$ & 433 & 434 & $0.0098 \pm 0.0003$ & $3.7 \pm 0.2$ \\
$\mathbf{1 e}$ & 427 & 428 & $0.0071 \pm 0.0001$ & $1.60 \pm 0.05$ \\
$\mathbf{1 f}$ & 428 & 426 & $0.006 \pm 0.001$ & $0.72 \pm 0.01$ \\
$\mathbf{1 g}$ & 435 & 436 & $0.0120 \pm 0.0002$ & $4.92 \pm 0.06$ \\
$\mathbf{1 h}$ & 437 & 435 & $0.0068 \pm 0.0001$ & $4.8 \pm 0.1$ \\
$\mathbf{1 i}$ & 434 & 433 & $0.0120 \pm 0.0002$ & $3.9 \pm 0.1$ \\
$\mathbf{1 j}$ & 445 & 446 & $0.0121 \pm 0.0001$ & $0.90 \pm 0.05$ \\
$\mathbf{1 k}$ & 432 & 438 & $0.062 \pm 0.002$ & $0.42 \pm 0.01$ \\
$\mathbf{1 l}$ & 442 & 444 & $0.0058 \pm 0.0002$ & $5.9 \pm 0.1$ \\
$\mathbf{1 m}$ & 444 & 408 & $0.012 \pm 0.001$ & $3.60 \pm 0.05$ \\
$\mathbf{1 n}$ & 448 & 438 & $0.007 \pm 0.001$ & $0.70 \pm 0.05$ \\
$\mathbf{1 0}$ & 472 & 478 & $0.007 \pm 0.001$ & $0.01 \pm 0.01$ \\
$\mathbf{2}$ & 429 & 424 & $0.206 \pm 0.001$ & $0.110 \pm 0.002$ \\
\hline
\end{tabular}

${ }^{\mathrm{a}}$ Excitation at $360 \mathrm{~nm}$.

The maximum wavelength for the chemiluminescent emission of all compounds seems to be limited within the range $425-450 \mathrm{~nm}$, right in the blue region of the spectrum, except for the nitro-substituted derivative 1o. In addition, it can be noted that the emission maxima for all compounds but $\mathbf{1 n}$ and $\mathbf{1 m}$ do not differ significantly from chemiluminescence to fluorescence, which is an indication that the high-energy intermediate directly forms the species that is responsible for the emission without complex bimolecular excited states or other unknown phenomena. The reason for the wavelength shift of $\mathbf{1 n}$ and $\mathbf{1 m}$ will be addressed in further publications. 


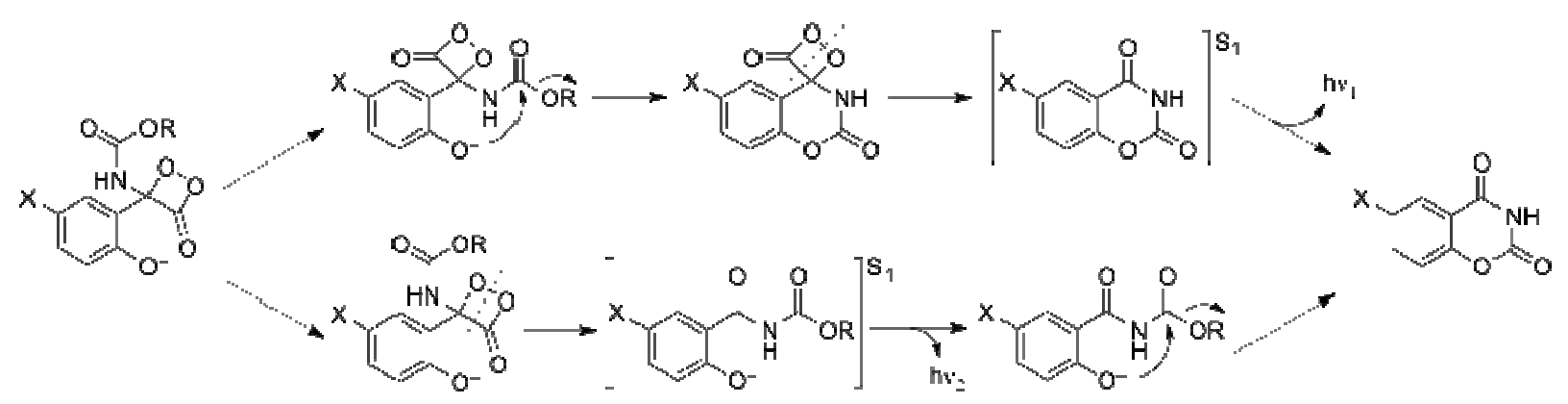

Scheme 4. Two possible pathways for the formation of structurally different emissive species.

The decay from the electronically excited state to the ground state, i.e. fluorescence, has a very fast rate constant $\left(k_{\mathrm{F}}\right)$ of $c a .10^{9} \mathrm{~s}^{-1}$ for spin-allowed transitions; this value is much faster than any competing chemical process, therefore, it can be postulated that the emission wavelength and overall emission profile is directly correlated to the emitting species, before it undergoes any chemical transformation, such as the cyclization showed in Scheme 4, which depicts two possible pathways for the formation of emissive species. The upper path displays a 1,2-dioxetandione that is stable enough to withstand as the phenolate attacks the nearby carbamate carbonyl group, forming a cyclic compound attached in a spiro fashion to the 1,2dioxetanone, which subsequently cleaves, producing a cyclic compound at the excited state, as the species responsible for the emission at a wavelength corresponding to an energy $h v_{1}$. The other possibility is that the 1,2-dioxetanone cleaves faster than the nucleophilic attack of the phenolate, producing a different excited state, with an emission at wavelengths corresponding to an energy $\mathrm{h} v_{2}$; the phenolate then produces a cyclization forming the same product as the first reaction. This final cyclic product was isolated and identified via NMR and MS. To differentiate between the two pathways, the emission wavelength has to be correlated to each species produced.

It is important to emphasize, for the following discussion, that any analysis regarding the reaction rate is restricted to effects on the transition state at the chemiexcitation step, since it is the rate-determining step. In a recent article, ${ }^{5}$ we demonstrated that the emission rate constant is indeed the decomposition rate constant; the rate constant for the emission was determined with and without activator, and since we reported that this rate constant increases linearly with the activator concentration, we could affirm that the activator is accelerating (i.e., catalyzing) the rate-determining step - the chemiluminescent decomposition of the 1,2-dioxetanone following the CIEEL mechanism. The effects on the emission quantum yield can be related to the whole process, since there is a cumulative formation of several species and the individual formation yield of each species will add to the combined yield of the excited states, which are, in turn, solely responsible for the light emission.

The reaction rate for the chemiluminescent emission follows a clear first-order decay, as expected, since the mechanism involves the formation of an intermediate 1,2-dioxetanone which 
cleaves in a unimolecular, rate-determining step, emitting light. Therefore, the emission rates observed are directly correlated to the stability of the intermediate 1,2-dioxetanone.

It is clear, observing the series 1a-f and 1g-o, that fluorine has the capacity of producing high chemiexcitation yields, compared to chlorine and bromine; the reaction rates also follow the same tendency, being higher for fluorine. Since the cleavage of the peroxidic intermediate $\mathbf{7}$ is the rate-determining step, any effect on the reaction rates should be connected to an original effect on the chemiluminescent decomposition of 7 itself. It has been demonstrated that electron donating from a phenolate located at the ortho position of a 1,2-dioxetanone can enhance its decomposition enormously, at the same time lowering the emission quantum yield, ${ }^{17}$ but we are not sure if this is a suitable explanation for the observed behaviour; additionally, the measured reaction rates are very similar, and therefore do not yield any straightforward mechanistical interpretation. We are currently working on substitution patterns that are able to change the reaction rate in at least one order of magnitude, so we will left a more incisive explanation to a upcoming paper, since we gather all relevant data.

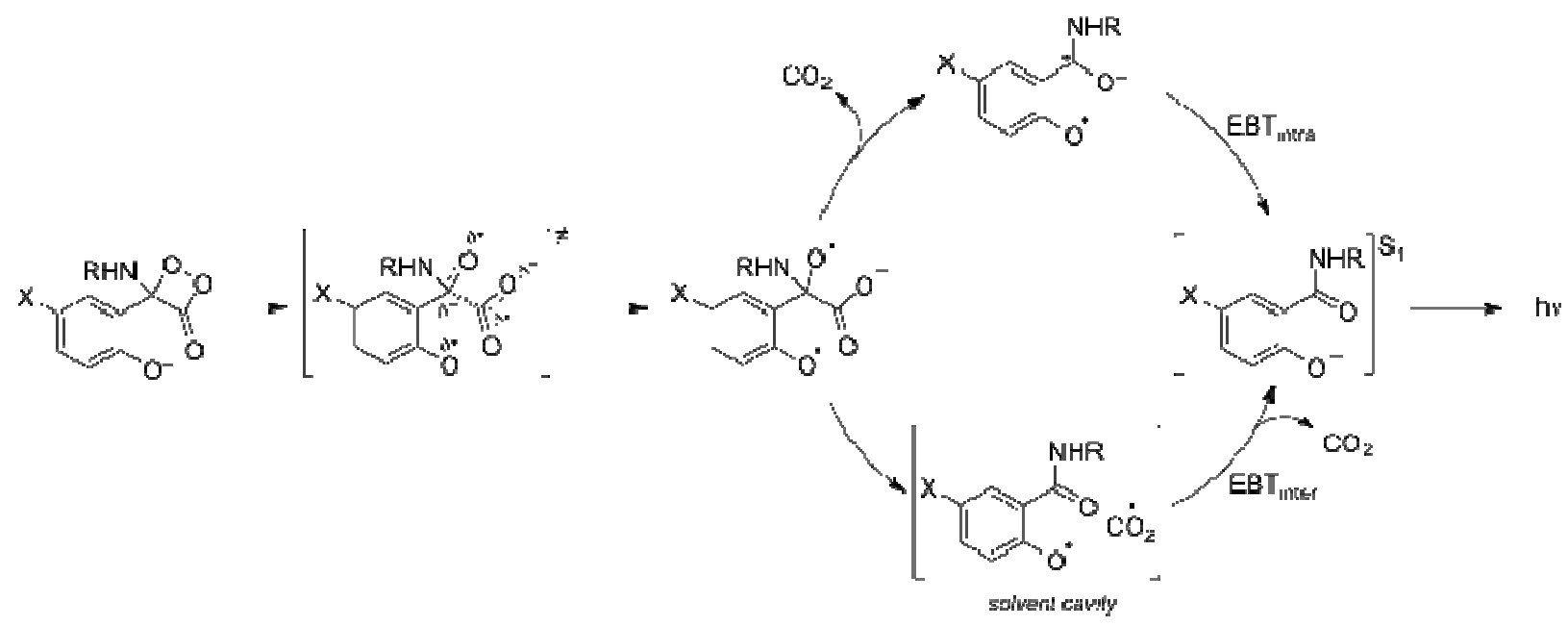

Scheme 5. The CIEEL mechanism applied to the induced decomposition of 1,2-dioxetanones.

It has been observed ${ }^{18}$ that the CIEEL mechanism, at least applied to 1,2-dioxetanes conjugated to an electron donor, can undergo two main chemiexcitation pathways, which are represented in Scheme 5. The electron donation from the phenolate to the peroxide induces the homolytic cleavage of the $\mathrm{O}-\mathrm{O}$ bond, forming, via a transition state TS1, a biradical that can follow two paths upon $\mathrm{C}-\mathrm{C}$ bond breakage: one is the formation of a biradical anion, which undergoes an electron back-transfer intramolecularly (EBT $\mathrm{Entra}_{\mathrm{a}}$ ), forming an emissive excited species; the other is the formation of a separate pair of a radical and carbon dioxide radical anion, which can transfer the electron back to the phenol moiety $\left(\mathrm{EBT}_{\mathrm{inter}}\right)$ before it diffuses away from the solvent cavity. Since the intramolecular back-transfer has higher yields, the difference in the quantum yields between the 2-coumaranones can be explained by the selectivity of the electron back-transfer pathway: the more the mechanism is shifted to an intramolecular reaction, the 
higher the quantum yields. We are, however, not convinced that the electron-donating has to occur via a ressonance pathway, since electron-donation over the space has been observed with high emission quantum yields, ${ }^{22}$ and may be a better suitable explanation for the efficient emission of coumaranones. However, it seems that the CIEEL mechanism is a good model for the chemiluminescent emission of those compounds.

However, since the chemiluminescence quantum yield $\left(\Phi_{\mathrm{CL}}\right)$ is determined from the product of the singlet quantum yield and the fluorescence quantum yield $\left(\Phi_{\mathrm{CL}}=\Phi_{\mathrm{S}} \mathrm{x} \Phi_{\mathrm{F}}\right)$, the singlet quantum yields should be the basis for this discussion. However, assuming that the fluorescence quantum yield remains almost constant, the analysis above should be regarded as valid.

One important result is that 2-coumaranones containing a propargyl (1h) and an azide (1i) moiety have very good emission quantum yields, $0.048 \pm 0.001$ and $0.039 \pm 0.001 \mathrm{E} \mathrm{mol}^{-1}$, respectively, which are higher than luminol $\left(0.0114 \pm 0.0006 \mathrm{E} \mathrm{mol}^{-1}\right)$. Those compounds have a potential application in bioanalytical assays, since they can be easily coupled to several modified biomolecules via a 1,3-cycloaddition reaction and be used as a kind of tag, easily revealed by base addition or different enzymes. Current research is taking place to evaluate the applicability of these compounds in aqueous media.

\section{Conclusions}

A series of 16 new 2-coumaranones has been synthesized by an optimized one-pot TscherniacEinhorn procedure, and the chemiluminescence emission of those compounds was examined in detail. As an outstanding result we were able to present new chemiluminescence substrates in the shape of carbamate substituted 2-coumaranones. Due to their easy synthesis and in addition, to their high emission quantum yields they are suitable substitutes for applications in bioassays. Also, some mechanistical aspects have been addressed, confirming a pathway able to produce high yields of excited states upon formal oxidation of the 2-coumaranones in the presence of base and oxygen.

\section{Experimental Section}

General. All reagents were obtained from commercial sources (Sigma Aldrich, TCI or Acros Organics) and used as received. The solvents were obtained with the synthesis quality and used as received; when marked as "dry", the solvent was dried with the usual method and distilled under nitrogen atmosphere. The progress of the syntheses was followed by thin layer chromatography (TLC, Merck, silicagel $60 \mathrm{~F}_{254}$ ) analyzed under UV light (254 and $366 \mathrm{~nm}$ ).

UV-Vis, fluorescence and chemiluminescence spectrophotometry. UV-vis, fluorescence and chemiluminescence spectra were obtained on a UV-Vis spectrophotometer or spectrofluorimeter with a cell holder thermostated at $20^{\circ} \mathrm{C}$ by a water-circulating bath. 
Kinetic chemiluminescence assays. All measurements were made in a quartz cuvette, with final volume $2.0 \mathrm{~mL}$ and concentration of $1 \times 10^{-5} \mathrm{~mol} \mathrm{~L}^{-1}$ of $\mathbf{1}$ and 2 in acetonitrile, in a spectrofluorimeter fitted with a cell holder thermostated at $25^{\circ} \mathrm{C}$ by a water-circulating bath. The reaction was started by addition of $30 \mu \mathrm{L}$ of $\mathrm{DBU}\left(67 \times 10^{-3} \mathrm{~mol} \mathrm{~L}^{-1}\right)$, and the chemiluminescence light intensity decay was followed for at least three half-lives. The light emission intensity was registered in arbitrary units (a.u. $\mathrm{s}^{-1}$ ) and was transformed into absolute light units $\left(\mathrm{E} \mathrm{s}^{-1}\right)$ by using the luminol standard. Light emission time profiles were fitted by means of a first-order exponential decay equation, resulting in the determination of the observed rate constants $\left(k_{\mathrm{obs}}\right)$ in $\mathrm{s}^{-1}$.

Chemiluminescence quantum yield $\left(\boldsymbol{\Phi}_{\mathbf{C L}}\right)$. The chemiluminescence quantum yields $\left(\Phi_{\mathrm{CL}}\right)$ for the reaction of $\mathbf{1}$ or $\mathbf{2}$ with DBU in acetonitrile were determined accordingly to a known procedure, ${ }^{19}$ using luminol as secondary standard ${ }^{20,21}\left(\Phi_{\text {lum }}=(1.14 \pm 0.06) 10^{-2} \mathrm{E} \mathrm{mol}^{-1}\right.$, independent of the initial luminol concentration). The wavelength sensibility factor $\left(f_{\mathrm{PMT}}\right)$ was 1 since the wavelength of emission is near to the luminol emission wavelength $(428 \mathrm{~nm})$.

\section{General synthesis procedure}

In a round-bottom $250 \mathrm{~mL}$ flask fitted with magnetic stirring and a drying tube, 0.030 moles of the appropriate carbamate and 0.035 moles of glyoxylic acid monohydrate were dissolved in 100 $\mathrm{mL}$ of a 9:1 mixture of acetic and sulfuric acids. After $c a .5$ minutes, 0.030 moles of the phenol were added, and the stirring was kept at room temperature and the reaction progress was followed by TLC until completion, which may take from one to several days. After this period, the reaction mixture was poured in $400 \mathrm{~mL}$ of distilled water, with precipitation of the reaction product, which was promptly filtered and washed until tested negative for acid. The mother liquor was extracted with chloroform or ethyl acetate, the organic layer was separated, dried with sodium sulfate and dried in vacuum. The two fractions containing the product were combined and recrystallized from ethanol.

Methyl (5-fluoro-2-oxo-2,3-dihydrobenzofuran-3-yl)carbamate (1a). From methyl carbamate, glyoxylic acid monohydrate and 4-fluorophenol; after 24 hours of stirring, the product starts to fall off, and the total reaction time was 48 hours. White powder, $43 \%, \mathrm{mp} 198{ }^{\circ} \mathrm{C}$. ${ }^{1} \mathrm{H}$ NMR $(250$ MHz, DMSO) $\delta 8.40$ (d, J 7.7 Hz, 1H), 7.35 - 6.99 (m, 3H), 5.35 (d, J 7.6 Hz, 1H), 3.53 (s, 3H). ${ }^{13} \mathrm{C}$ NMR (63 MHz, DMSO) $\delta 174.25,161.23,157.41,156.60,149.85,128.50,116.49,112.14$, 52.56, 31.11. MS (EI): m/z (\%) 225 [M+1 (100), 197 (80), 165 (95), 151 (45), 137 (50), 59 (45). HR-MS: 225.04373 (theo.), 225.04361 (obs.). IR (ATR) $\mathrm{cm}^{-1}$ 3371, 2970, 2900, 1789, 1697 , 1519, 1265, 1070, 1018, 902, 833, 786.

Methyl (5-chloro-2-oxo-2,3-dihydrobenzofuran-3-yl)carbamate (1b). From methyl carbamate, glyoxylic acid monohydrate and 4-chlorophenol; 6 days reaction time; white powder, 36\%, mp $200{ }^{\circ} \mathrm{C} .{ }^{1} \mathrm{H}$ NMR (300 MHz, DMSO) $\delta 8.42$ (d, J 7.6 Hz, 1H), $7.50-7.29$ (m, 2H), $7.23(\mathrm{~d}, J 8.5 \mathrm{~Hz}, 1 \mathrm{H}), 5.35(\mathrm{~d}, J 7.5 \mathrm{~Hz}, 1 \mathrm{H}), 3.53(\mathrm{~s}, 3 \mathrm{H}) .{ }^{13} \mathrm{C}$ NMR: $(75 \mathrm{MHz}, \mathrm{DMSO}) \delta$ $173.80,156.62,152.52,129.78,128.87,128.60,124.49,112.62,52.61,52.31 . \mathrm{MS}(\mathrm{EI}) \mathrm{m} / \mathrm{z}(\%)$ 
$241\left[\mathrm{M}^{+}\right]$(100), 213 (75), 181 (80), 154 (40), 59 (40). HR-MS: 241.01418 (theo.), 241.01427 (obs.). IR (ATR) cm $\mathrm{cm}^{-1} 3379,2970,2900,1797,1705,1519,1465,1219,1134,1080,1018$.

Methyl (5-bromo-2-oxo-2,3-dihydrobenzofuran-3-yl)carbamate (1c). From methyl carbamate, glyoxylic acid monohydrate and 4-bromophenol; 7 days reaction time; white powder, 27\%, mp $208{ }^{\circ} \mathrm{C} .{ }^{1} \mathrm{H}$ NMR (300 MHz, DMSO) $\delta 8.41$ (d, J 7.6 Hz, 1H), $7.62-7.50$ (m, 2H), $7.18(\mathrm{~d}, J 8.5 \mathrm{~Hz}, 1 \mathrm{H}), 5.35(\mathrm{~d}, J 7.6 \mathrm{~Hz}, 1 \mathrm{H}), 3.53(\mathrm{~s}, 3 \mathrm{H}) .{ }^{13} \mathrm{C}$ NMR $(75 \mathrm{MHz}, \mathrm{DMSO}) \delta$ $173.66,156.62,152.97,132.65,129.29,127.26,116.30,113.11,52.62,52.20 . \mathrm{MS}(\mathrm{EI}) \mathrm{m} / z(\%)$ $287\left[\mathrm{M}^{+}+2\right]$ (100), $285\left[\mathrm{M}^{+}\right]$(95), 259 (80), 63 (85), 59 (85). HR-MS: 284.96367 (theo.), 284.96343 (obs.). IR (ATR) $\mathrm{cm}^{-1}$ 3356, 1828, 1690, 1527, 1465, 1080, 1018, 894.

Ethyl (5-fluoro-2-oxo-2,3-dihydrobenzofuran-3-yl)carbamate (1d). From ethyl carbamate, glyoxylic acid monohydrate and 4-fluorophenol. 7 days reaction time; white crystals (long needles), 24\%, mp $156{ }^{\circ} \mathrm{C} .{ }^{1} \mathrm{H}$ NMR (400 MHz, DMSO) $\delta 8.35$ (d, J 7.6 Hz, 1H), 7.28 - 7.12 $(\mathrm{m}, 3 \mathrm{H}), 5.34(\mathrm{~d}, J 7.6 \mathrm{~Hz}, 1 \mathrm{H}), 4.08-3.89(\mathrm{~m}, 2 \mathrm{H}), 1.14(\mathrm{t}, J 7.1 \mathrm{~Hz}, 3 \mathrm{H}) .{ }^{13} \mathrm{C}$ NMR $(101 \mathrm{MHz}$, DMSO) $\delta 174.29,160.52,158.14,156.19,149.83,128.49,116.15,112.20,61.25,52.63,14.85$. MS (ESI) $m / z(\%) 262.0\left[\mathrm{M}+\mathrm{Na}^{+}\right]$(100). HR-MS: 262.04915 ([M+Na $\left.{ }^{+}\right]$, theo.), 262.04907 (obs.). IR (ATR) cm $\mathrm{cm}^{-1} 3371,2985,2924,1797,1697,1519,1103,1072,1026,887,825$.

Ethyl (5-chloro-2-oxo-2,3-dihydrobenzofuran-3-yl)carbamate (1e). From ethyl carbamate, glyoxylic acid monohydrate and 4-chlorophenol; 100 hours reaction time; white powder, 20\%, mp $170{ }^{\circ} \mathrm{C} .{ }^{1} \mathrm{H}$ NMR $(250 \mathrm{MHz}, \mathrm{DMSO}) \delta 8.36(\mathrm{~d}, J 7.6 \mathrm{~Hz}, 1 \mathrm{H}), 7.50-7.30(\mathrm{~m}, 2 \mathrm{H}), 7.23(\mathrm{~d}, J$ $8.5 \mathrm{~Hz}, 1 \mathrm{H}), 5.34(\mathrm{~d}, J 7.6 \mathrm{~Hz}, 1 \mathrm{H}), 4.07-3.87(\mathrm{~m}, 2 \mathrm{H}), 1.14(\mathrm{t}, J 7.1 \mathrm{~Hz}, 3 \mathrm{H}) .{ }^{13} \mathrm{C}$ NMR $(63$ MHz, DMSO) $\delta 173.82,156.18,152.50,129.73,128.95,128.58,124.44,112.59,61.28,52.26$, 14.82. MS (EI) m/z (\%) $255\left[\mathrm{M}^{+}\right]$(80), 227 (50), 182 (60), 167 (45), 155 (100), 127 (30). HRMS: 255.02983 (theo.), 255.02991 (obs.). IR (ATR) cm $\mathrm{cm}^{-1} 3332,2985,1828,1697,1535,1465$, 1064, 1010, 879.

Ethyl (5-bromo-2-oxo-2,3-dihydrobenzofuran-3-yl)carbamate (1f). From ethyl carbamate, glyoxylic acid monohydrate and 4-bromophenol; 100 hours reaction time; white powder, 20\%, mp $182{ }^{\circ} \mathrm{C} .{ }^{1} \mathrm{H}$ NMR $(250 \mathrm{MHz}, \mathrm{DMSO}) \delta 8.35(\mathrm{~d}, J 7.6 \mathrm{~Hz}, 1 \mathrm{H}), 7.62-7.38(\mathrm{~m}, 2 \mathrm{H}), 7.17(\mathrm{~d}, J$ $8.5 \mathrm{~Hz}, 1 \mathrm{H}), 5.33(\mathrm{~d}, J 7.6 \mathrm{~Hz}, 1 \mathrm{H}), 4.16-3.70(\mathrm{~m}, 2 \mathrm{H}), 1.13(\mathrm{t}, J 7.1 \mathrm{~Hz}, 3 \mathrm{H}) .{ }^{13} \mathrm{C}$ NMR $(63$ MHz, DMSO) $\delta 173.68,156.18,152.95,132.61,129.37,127.21,116.27,113.08,61.29,52.15$, 14.82. MS (EI) m/z (\%) $301[\mathrm{M}+2](70), 299\left[\mathrm{M}^{+}\right](80), 273$ (60), 271 (45), 228 (55), 226 (70), 201 (80), 199 (100), 75 (40), 63 (55). HR-MS: 298.97932 (theo.), 298.97956 (obs.). IR (ATR) $\mathrm{cm}^{-1} 3348,2985,2900,1828,1698,1527,1465,1072,1026,887,779$.

Neopentyl (5-fluoro-2-oxo-2,3-dihydrobenzofuran-3-yl)carbamate $\quad(1 \mathrm{~g}) . \quad$ From 2,2dimethylpropanyl carbamate, glyoxylic acid monohydrate and 4-fluorophenol; 72 hours reaction time; white powder, 46\%, mp $142{ }^{\circ} \mathrm{C} .{ }^{1} \mathrm{H}$ NMR (250 MHz, DMSO) $\delta 8.38(\mathrm{~d}, J=7.7 \mathrm{~Hz}, 1 \mathrm{H})$, $7.34-7.04(\mathrm{~m}, 3 \mathrm{H}), 5.34(\mathrm{~d}, J=7.7 \mathrm{~Hz}, 1 \mathrm{H}), 3.75-3.57(\mathrm{~m}, 2 \mathrm{H}), 0.86(\mathrm{~s}, 7 \mathrm{H}), 0.57(\mathrm{~s}, 2 \mathrm{H}) .{ }^{13} \mathrm{C}$ NMR (63 MHz, DMSO) $\delta$ 174.26, 161.23, 156.43, 149.86, 128.65, 116.41, 112.03, 111.63, 74.09, 52.64, 31.79, 26.52. MS (ESI) $m / z$ (\%) $304.0\left[\mathrm{M}+\mathrm{Na}^{+}\right]$(100). HR-MS: 304.09610 ([M+Na $\left.{ }^{+}\right]$, theo.), 304.09468 (obs.). IR (ATR) $\mathrm{cm}^{-1} 3441,2958,2870,1816,1693,1512,1477$, $1261,1211,1103,1060,1010,894,806,779$. 
X-ray crystallography data available at the supporting information.

Prop-2-yn-1-yl (5-fluoro-2-oxo-2,3-dihydrobenzofuran-3-yl)carbamate (1h). From propargyl carbamate, ${ }^{22}$ glyoxylic acid monohydrate and 4-fluorophenol. 72 hours reaction time; white powder, 49\%, mp $171{ }^{\circ} \mathrm{C}$ (recryst. from MeOH). ${ }^{1} \mathrm{H}$ NMR (250 MHz, DMSO) $\delta 8.58(\mathrm{~d}, J 7.6$ $\mathrm{Hz}, 1 \mathrm{H}), 7.38-7.11(\mathrm{~m}, 3 \mathrm{H}), 5.41(\mathrm{~d}, J 7.6 \mathrm{~Hz}, 1 \mathrm{H}), 4.63(\mathrm{~s}, 2 \mathrm{H}), 3.51(\mathrm{~s}, 1 \mathrm{H}) .{ }^{13} \mathrm{C}$ NMR $(63$ MHz, DMSO) $\delta 174.02,161.25,157.43,155.32,149.86,128.25,128.10,116.62,112.20,78.14$, 52.92, 52.67. MS (ESI) $\mathrm{m} / z$ (\%) $272.0\left[\mathrm{M}+\mathrm{Na}^{+}\right]$(100). HR-MS: $272.03350\left(\left[\mathrm{M}+\mathrm{Na}^{+}\right]\right.$, theo.), 272.03447 (obs.). IR (ATR) $\mathrm{cm}^{-1}$ 3271, 3066, 2125, 1809, 1693, 1539, 1477, 1273, 1107, 1076, $1013,875,783,678$.

6-Azidohexyl (5-fluoro-2-oxo-2,3-dihydrobenzofuran-3-yl)carbamate (1i). From 6azidohexyl carbamate (prepared according to [12] using $\mathrm{Et}_{2} \mathrm{O}$ as solvent), glyoxylic acid monohydrate and 4-fluorophenol. 72 hours reaction time; purification of crude product by column chomatography ( silica gel, hexane/AcOEt 2:1 to 1:4) and subsequent crystallization from methanol; white powder, $10 \%$, mp $91{ }^{\circ} \mathrm{C} .{ }^{1} \mathrm{H}$ NMR (250 MHz, DMSO) $\delta 8.34$ (d, J 7.7 Hz, 1H), $7.33-7.09(\mathrm{~m}, 3 \mathrm{H}), 5.33(\mathrm{~d}, J 7.5 \mathrm{~Hz}, 1 \mathrm{H}), 3.92(\mathrm{t}, J 6.2 \mathrm{~Hz}, 2 \mathrm{H}), 1.66-1.10(\mathrm{~m}, 10 \mathrm{H}) .{ }^{13} \mathrm{C}$ NMR (63 MHz, DMSO) $\delta 174.24,156.26,154.18,149.83,116.42,116.04,112.21,112.07$, $65.09,52.62,50.96,28.75,28.55,26.17,25.23$. MS (ESI) $\mathrm{m} / z(\%) 259.0\left[\mathrm{M}+\mathrm{Na}^{+}\right](100)$. HRMS: 359.11315 ([M+Na $\left.{ }^{+}\right]$, theo.), 359.11373 (obs.). IR (ATR) $\mathrm{cm}^{-1} 3672,3371,2939,2090$, 1797, 1697, 1519, 1481, 1219, 1107, 1076, 1037, 1010, 902, 821, 783.

4-Fluorophenyl (5-fluoro-2-oxo-2,3-dihydrobenzofuran-3-yl)carbamate (1j). From 4fluorophenyl carbamate, glyoxylic acid monohydrate and 4-fluorophenol. 72 hours reaction time; white powder, $71 \%$ crude, $51 \%$ recryst. from ethanol, mp $250{ }^{\circ} \mathrm{C}$ (dec.). ${ }^{1} \mathrm{H}$ NMR $(300 \mathrm{MHz}$, DMSO) $\delta 8.86(\mathrm{dd}, J 7.6 \mathrm{~Hz}, 1 \mathrm{H}), 7.26(\mathrm{~m}, 7 \mathrm{H}), 5.55(\mathrm{~d}, J 7.6 \mathrm{~Hz}, 1 \mathrm{H}) .{ }^{13} \mathrm{C} \mathrm{NMR}(126 \mathrm{MHz}$, DMSO) $\delta 173.97,160.69,154.33,149.79,147.28,127.84,124.56,123.25,117.12,115.81$, 112.99, 111.66, 52.26. MS (EI) m/z (\%) $305\left[\mathrm{M}^{+}\right]$(20), 212 (10), 169 (10), 166 (15), 151 (20), 139 (10), 122 (10), 112 (100), 95 (40), 83 (30), 75 (10), 64 (5), 57 (10), 45 (5), 43 (5), 28 (5). HR-MS: 305.04996 (theo.), 305.05020 (obs.). IR (ATR) $\mathrm{cm}^{-1} 3456,3317,3016$ (b), 1745, 1435, $1365,1211,1095,1010,833,763,640$.

2-Bromophenyl (5-fluoro-2-oxo-2,3-dihydrobenzofuran-3-yl)carbamate (1k). From 2bromophenyl carbamate, glyoxylic acid monohydrate and 4-fluorophenol. 48 hours reaction time; white powder, 68\%, mp $220{ }^{\circ} \mathrm{C} .{ }^{1} \mathrm{H}$ NMR (300 MHz, DMSO) $\delta 9.21$ (d, $J 7.6 \mathrm{~Hz}, 1 \mathrm{H}$ ), $7.67(\mathrm{~d}, J 7.5 \mathrm{~Hz}, 1 \mathrm{H}), 7.40(\mathrm{t}, J 7.6 \mathrm{~Hz}, 1 \mathrm{H}), 7.33-7.11(\mathrm{~m}, 5 \mathrm{H}), 5.56(\mathrm{~d}, J 7.5 \mathrm{~Hz}, 1 \mathrm{H}) .{ }^{13} \mathrm{C}$ NMR (126 MHz, DMSO) $\delta 173.72,160.40,157.08,153.55,149.86,133.00,132.81,130.02$, 128.69, 127.90, 125.50, 124.27, 116.47, 112.97, 52.27. MS (EI) $\mathrm{m} / z$ (\%) 368 [M+2] (30), 366 $\left[\mathrm{M}^{+}\right]$(35), 340 (5), 174 (100), 172 (95), 166 (25), 151 (30), 137 (5), 123 (5), 122 (5), 95 (5), 75 (5), 63 (5). HR-MS: 364.96989 (theo.), 364.96954 (obs.). IR (ATR) cm $\mathrm{cm}^{-1} 3456,3340,3016$ (b), 1743, 1519, 1442, 1355, 1211, 1041, 1002.

Mesityl (5-fluoro-2-oxo-2,3-dihydrobenzofuran-3-yl)carbamate (11). From mesityl carbamate, glyoxylic acid monohydrate and 4-fluorophenol. 72 hours reaction time; white powder, 87\%, mp $245{ }^{\circ} \mathrm{C} .{ }^{1} \mathrm{H}$ NMR (300 MHz, DMSO) $\delta 8.99(\mathrm{~d}, J 7.4 \mathrm{~Hz}, 1 \mathrm{H}), 7.24(\mathrm{~m}, 3 \mathrm{H})$, 
$6.85(\mathrm{~m}, 2 \mathrm{H}), 5.50(\mathrm{~d}, J 7.4 \mathrm{~Hz}, 1 \mathrm{H}), 2.19(\mathrm{~s}, 3 \mathrm{H}), 2.02(\mathrm{~s}, 6 \mathrm{H}) .{ }^{13} \mathrm{C}$ NMR $(126 \mathrm{MHz}, \mathrm{DMSO}) \delta$ $174.07,163.13,160.84,152.88,140.61,138.19,134.89,132.00,130.30,125.16,117.36,112.70$, 69.31, 23.53, 15.57. MS (EI) $m / z(\%) 329$ [M $\mathrm{M}^{+}$(15), 151 (5), 136 (100), 121 (20), 91 (5), 77 (2). HR-MS: 329.10633 (theo.), 329.10613 (obs.). IR (ATR) cm $\mathrm{cm}^{-1}$ 3456, 3325, 3016 (b), 1739, 1519, 1442, 1365, 1211, 1126, 1072, 894, 779.

4-Methoxyphenyl (5-fluoro-2-oxo-2,3-dihydrobenzofuran-3-yl)carbamate (1m).From 4methoxyphenyl carbamate, glyoxylic acid monohydrate and 4-fluorophenol. 72 hours reaction time; white powder, 31\%, mp $156{ }^{\circ} \mathrm{C}$ (dec.). ${ }^{1} \mathrm{H}$ NMR (300 MHz, DMSO) $\delta 8.56$ (d, J $6.0 \mathrm{~Hz}$, 1H), $7.08-6.89(\mathrm{~m}, 7 \mathrm{H}), 5.53(\mathrm{~s}, 1 \mathrm{H}), 3.76$ (s, 3H). ${ }^{13} \mathrm{C}$ NMR (126 MHz, DMSO) $\delta 172.41$, 156.97, 154.72, 150.83, 146.19, 144.62, 143.44, 133.59, 123.69, 122.42, 115.38, 114.07, 56.48, 55.25. MS (EI) m/z (\%) $317\left[\mathrm{M}^{+}\right]$(15), 124 (100), 109 (25), 95 (5), 81 (5). HR-MS: 317.06995 (theo.), 317.07015 (obs.). IR (ATR) $\mathrm{cm}^{-1} 3271,3008,2947,2839,1746,1489,1365,1200,1026$, 825,779 .

4-Acetamido (5-fluoro-2-oxo-2,3-dihydrobenzofuran-3-yl)carbamate (1n). From 4acetamidophenyl carbamate, glyoxylic acid monohydrate and 4-fluorophenol. 72 hours reaction time; pale yellow powder, 36\%, mp $208{ }^{\circ} \mathrm{C}$ (dec.). ${ }^{1} \mathrm{H}$ NMR (300 MHz, DMSO) $\delta 9.97$ (s, 1H), $8.94(\mathrm{~d}, J 7.8 \mathrm{~Hz}, 1 \mathrm{H}), 7.54(\mathrm{~d}, J 8.9 \mathrm{~Hz}, 2 \mathrm{H}), 7.40-7.17(\mathrm{~m}, 3 \mathrm{H}), 7.02(\mathrm{~d}, J 8.9 \mathrm{~Hz}, 2 \mathrm{H}), 5.52$ $(\mathrm{d}, J 7.7 \mathrm{~Hz}, 1 \mathrm{H}), 2.02$ (s, 3H). ${ }^{13} \mathrm{C}$ NMR $(126 \mathrm{MHz}, \mathrm{DMSO}) \delta 172.24,168.61,154.89,151.85$, $146.58,136.89,122.95,121.64,120.83,119.59,117.35,116.01,51.87,23.98 . \mathrm{MS}(\mathrm{EI}) \mathrm{m} / \mathrm{z}(\%)$ $345\left[\mathrm{M}^{+1}\right]$ (20), $344\left[\mathrm{M}^{+}\right]$(10), 302 (10), 194 (5), 151 (75), 109 (100), 80 (10), 60 (5), 44 (20). HR-MS: 344.08085 (theo.), 344.08097 (obs.). IR (ATR) cm $\mathrm{cm}^{-1}$ 3456, 3363, 3317, 3016 (b), 1745, 1666, 1496, 1365, 1211, 1149, 1103, 1018, 817, 763, 640.

4-Nitrophenyl (5-fluoro-2-oxo-2,3-dihydrobenzofuran-3-yl)carbamate (10). From 4nitrophenyl carbamate, glyoxylic acid monohydrate and 4-fluorophenol; 48 hours reaction time; pale yellow powder, 55\%, mp $210{ }^{\circ} \mathrm{C}$ (dec.). ${ }^{1} \mathrm{H}$ NMR (500 MHz, DMSO) $\delta 9.26(\mathrm{~d}, J 7.9 \mathrm{~Hz}$, 1H), $8.29(\mathrm{~m}, 3 \mathrm{H}), 7.45(\mathrm{~d}, 4 \mathrm{H}), 5.63(\mathrm{~d}, J 7.8 \mathrm{~Hz}, 1 \mathrm{H}) .{ }^{13} \mathrm{C}$ NMR (126 MHz, DMSO) $\delta 173.77$, $160.35,158.46,155.88,153.43,149.86,145.03,127.63,125.71,122.98,116.82,112.28,52.78$. MS (EI) m/z (\%) $332\left[\mathrm{M}^{+}\right](80), 193$ (100), 165 (100), 151 (90), 139 (95), 137 (60), 123 (50), 109 (55), 95 (40), 81 (15), 75 (20), 65 (35), 50 (10), 39 (15), 28 (20). HR-MS: 332.04446 (theo.), 332.04418 (obs.). IR (ATR) $\mathrm{cm}^{-1} 3456,3317,3016,1730,1442,1365,1211,1010,902,871$, $817,779,609$.

Ethyl (2-oxo-1,2-dihydronaphtho[2,1-b]furan-1-yl)carbamate (2). From ethyl carbamate, glyoxylic acid monohydrate and $\beta$-Napthol. 72 hours reaction time; white powder, 29\% (rekrist. EtOH), mp $230{ }^{\circ} \mathrm{C} .1 \mathrm{H}$ NMR (400 MHz, DMSO) $\delta 8.63$ (d, J 7.2 Hz, 1H), 8.01 (dd, J 8.5, 2.9 $\mathrm{Hz}, 2 \mathrm{H}), 7.87$ (d, J 8.3 Hz, 1H), 7.62 (t, J 11.1, 4.0 Hz, 1H), 7.48 (d+s, J 7.8, 6.3 Hz, 2H), 5.74 (d, J 7.6 Hz, 1H), 3.53 (s, 3H). 13C NMR (101 MHz, DMSO) $\delta 174.68,156.48,151.73,131.03$, $130.91,129.68,129.31,128.21,125.26,122.72,118.57,112.01,52.54$. MS EI: 258 [M+1]+ (20), $257\left[\mathrm{M}^{+}\right]$(100), 229 (30), 214 (25), 198 (80), 183 (20), 169 (50), 152 (5), 140 (5), 127 (10), 115 (30), 113 (5), 89 (5), 63 (3), 59 (5). HR-MS: 280.05857 ([M+Na], theo.), 280.05866 (obs.). 
IR (ATR) $\mathrm{cm}^{-1} 3356,1805,1689,1635,1577,1519,1450,1327,1273,1242,1211,1111,1056$, $1014,991,810,748,628$.

\section{Acknowledgements}

This work was partially supported by the São Paulo Research Foundation, FAPESP (L.F.M.L.C., grant 2012/02428-5). S.S. and P.O. are thanking the University of Oregon and in particular M. M. Haley and D. W. Johnson. S.S. is thanking the Friedrich-Ebert-Stiftung for financial support.

\section{References}

1. Bowie, R.; Sanders, M.G.; Worsfold, P. J. J. Biolumin. Chemilumin. 1996, 11,61-90. http://dx.doi.org/10.1002/(SICI)1099-1271(199603)11:2<61::AID-BIO406>3.0.CO;2-O

2. Schramm, S.; Weiß, D.; Brandl, H.; Beckert, R.; Görls, H.; Roca-Sanjuán, D.; Navizet, I. Arkivoc 2013, 3, 174-188. http://dx.doi.org/10.3998/ark.5550190.0014.314

3. Schramm, S.; Weiß, D.; Beckert, R. Luminescence 2012, 27, 159. http://dx.doi.org/10.1002/bio.2341

4. Schramm, S.; Weiß, D.; Beckert, R. Luminescence 2014, 29, 45. http://dx.doi.org/10.1002/bio.2699_2

5. Ciscato, L. F. M. L.; Bartoloni, F. H.; Colavite, A. S.; Weiss, D.; Beckert, R.; Schramm, S. Photochem. Photobiol. Sci. 2014, 13, 32-37. http://dx.doi.org/10.1039/C3PP50345C

6. Lofthouse, G. J; Suschitzky, H.; Wakefield, B.J.; Whittaker, R.A.; Tuck, B.J. Chem. Soc. Perkin Trans. 1 1979, 1634-1639. http://dx.doi.org/10.1039/p19790001634

7. Ishii, Y.; Hayashi, C.; Suzuki Y.; Hirano, T. Photochem. Photobiol. Sci. 2014, 13, 182-189. http://dx.doi.org/10.1039/C3PP50197C

8. Kondo, H.; Igarashi, T.; Maki, S.; Niwa, H.; Ikeda H.; Hirano, T. Tetrahedron Lett. 2005, 46, 7701-7704. http://dx.doi.org/10.1016/j.tetlet.2005.09.014

9. Stevani, C. V.; de Arruda Campos, I. P.; Baader, W. J. Chem. Soc. Perkin Trans. 2 1996, 8, 1645-1648. http://dx.doi.org/10.1039/P29960001645

10. Bartoloni, F. H.; Oliveira, M. A.; Augusto, F. A.; Ciscato, L. F. M. L.; Bastos, E. L.: Baader, W. J. J. Braz. Chem. Soc. 2012, 23, 2093. http://dx.doi.org/10.1590/S0103-50532012001100018

11. Tscherniac J. Verfahren zur Darstellung von Benzylphthalimiden, DE134979. 1901 
12. Einhorn, A.; Bischkopff, E.; Szelinski, B.; Schupp, G.; Spröngerts, E.; Ladisch, C.; Mauermayer, T. Liebigs Ann. Chem. 1905, 343, 207-305.

http://dx.doi.org/10.1002/jlac.19053430207

13. Matuszczak, B. Monatshefte für Chemie 1996, 127, 1291-1303. http://dx.doi.org/10.1007/BF00807797

14. Matuszczak, B. Pharmazie 1996, 51, 862-865.

15. Matuszczak, B. Monatshefte für Chemie 1997, 128, 945-951. http://dx.doi.org/10.1007/BF00807104

16. Matuszczak, B. J. Prakt. Chem. 1998, 340, 20-25. http://dx.doi.org/10.1002/prac.19983400104

17. Adam, W.; Trofimov, A. V. J. Org. Chem. 2000, 65, 6474 http://dx.doi.org/10.1021/jo000495a

18. Adam, W.; Trofimov, A.V. In: The Chemistry of Peroxides; Rappoport, Z. Ed.; Patai Series; Wiley: Chichester, 2006; Vol. 2, Part 2, pp1171-1209

19. Stevani, C. V.; da Silva, S. M.; Baader, W. J. Eur. J. Org. Chem. 2000, 24, 4037. http://dx.doi.org/10.1002/1099-0690(200012)2000:24<4037::AID-EJOC4037>3.0.CO;2-A

20. Lee, J.; Seliger, H. H. Photochem. Photobiol. 1965, 4, 1015 http://dx.doi.org/10.1111/j.1751-1097.1965.tb09293.x

21. Lee, J.; Seliger, H. H. Photochem. Photobiol. 1972, 15, 227 http://dx.doi.org/10.1111/j.1751-1097.1972.tb06241.x

22. Loev, B.; Kormendy, M. F. J. Org. Chem. 1963, 28, 3421. http://dx.doi.org/10.1021/jo01047a033

23. Ciscato, L. F. M. L.; Bartoloni, F. H.; Weiss, D.; Beckert, R.; Baader, W. J. J. Org. Chem. 2010, 75, 1211.

http://dx.doi.org/10.1021/jo1013405 